\title{
Atravessamento ético-político na experiência em pesquisa em História Social da Psicologia
}

\section{Ethical and political crossing in the experience in research in Social History of Psychology}

\section{Atravesamiento ético-político en la experiencia en la investigación en História Social de la Psicología}

\author{
Márcio Luis Costa* \\ Universidade Católica Dom Bosco - UCDB, Campo Grande, Mato Grosso do Sul, \\ Brasil
}

Gillianno M. de Castro**

Universidade Católica Dom Bosco - UCDB, Campo Grande, Mato Grosso do Sul, Brasil

\begin{abstract}
RESUMO
O objeto deste estudo é o atravessamento ético-político na pesquisa em História Social da Psicologia e tem como objetivo propor uma reflexão sobre o significado desse atravessamento e sua repercussão no referido campo de pesquisa. Trata-se de um estudo bibliográfico que busca promover o diálogo entre dois campos, o da Filosofia e o da pesquisa. A estratégia metodológica consiste em promover um diálogo entre o conceito ético-político, como possibilidade de atravessamento, e a prática em pesquisa, como campo que permite ser atravessado. Para tanto, lança-se mão de recursos lógicos e analisadores provenientes da Fenomenologia, da ética levinasiana e da política arendtiana. A Fenomenologia permite chegar a uma compreensão da atravessabilidade na pesquisa como experiência de aberturas, resistências e possibilidades. A política, por sua vez, permite fazer ver que a pesquisa se realiza no espaço público como espaço de alteridades. A ética, por sua vez, assinala para o horizonte no qual é possível pensar e realizar atravessamentos, isto é, o lugar que dá espaço às relações de alteridades.

Palavras-chave: ética, política, pesquisa, história da psicologia.
\end{abstract}

\section{ABSTRACT}

The object of study in this article is the ethical-political crossing in research in Social History of Psychology, and we propose a reflection on the meaning of crossing and its impact in that field of research. This is a bibliographical study that seeks to promote a dialogue between two fields: philosophy and research. The methodological strategy is to promote a dialogue between the concept of ethical-political as possible crossing and the practice as a research field that allows to be crossed. Therefore, it makes use of logic analyzers from Phenomenology of Levinas' ethics and Arendt's politics. In this discussion, Phenomenology allows reaching an understanding of crossing research and experience gaps, strengths and possibilities. On the 
other hand, politics permit to evidence that research takes place in the public space as alterities space. Ethics, however, points out to the horizon in which we are able to think and perform crossings, what means, the place that creates a space to relations of otherness.

Keywords: ethics, politics, research, history of psychology.

\section{RESUMEN}

El objeto del estudio es el atravesamiento ético-político en la investigación en História Social de la Psicología y tiene como objetivo proponer una reflexión sobre el significado de ese atravesamiento y sus repercusiones en el referido campo de investigación. Tratase de un estudio bibliográfico que busca promover el diálogo entre dos campos, el de la Filosofía y el de la investigación. La estratégia metodológica consiste en promover un diálogo entre el concepto de lo ético-político como posibilidad de atravesamiento y la práctica en investigación como campo que se permite atravesar. Para lograrlo, se hace uso de recursos lógicos y analisadores provenientes de la Fenomenología, de la ética levinasiana y de la política arendtiana. La Fenomenología permite llegar a una comprensión de la atravesabilidad en la investigación como experiencia de aperturas, resistencias y posibilidades. La política permite hacer ver que la investigación se realiza en el espacio público como espacio de alteridades. La ética señala el horizonte en el cual es posible pensar y realizar atravesamientos, es decir, el lugar que da espacio a las relaciones de alteridades.

Palabras clave: ética, política, investigación, historia da psicología.

\section{Introdução}

O objetivo deste estudo é propor um questionamento sobre o significado da ideia de atravessamento ético-político na prática em Pesquisa em História Social da Psicologia e como isso se faz presente desde quando o pesquisador se propõe a pesquisa como experiência até quando constrói uma narrativa performática que vai atravessá-lo e a outros, na forma de livro, artigo, conferência e outras produções. Entendemos pesquisa como uma experiência voltada para a construção do conhecimento científico, realizada no e como espaço público, podendo ser expressa e discutida tanto em seu percurso, quanto em seus resultados.

O espaço público dá-se enquanto habitado por alteridades (Arendt, 2007), no qual cada um é o outro do outro, diferença da diferença (Machado, 2009) e não indivíduo frente a outro indivíduo, desmitificando assim a compreensão de que se trata de um espaço de individualidades. Esse mesmo espaço é ético em virtude do dinamismo próprio da relação entre alteridades, isto é, relação interimpressiva, marcada pela sensibilidade como não indiferença (Costa, 2009, Lévinas, 1974), como bem ético e medida mesma do humano.

O bem ético ao longo da história assumiu várias facetas à medida que ia sendo reproposto nas distintas teorias éticas. Como isso se deu? 
Para compreender esse percurso, faz-se necessário recordar que a filosofia e a ciência aparecem na Ásia Menor como disciplina da pergunta, e não como escola de respostas; isto pode ser visto de forma muito clara nas inquietantes indagações dos assim chamados filósofos/cientistas pré-socráticos (Eggers Lan, 1986). Não muito longe dali, nem no tempo nem no espaço, é possível ver essa interrogação inaugurando as primeiras reflexões no campo da ética com o Sócrates de Platão (Platón, 1986). Parece-nos igualmente importante perceber que, já na Grécia antiga, a disciplina da pergunta começa a ser substituída por um discurso linear e normativo no campo da ética, como por exemplo, o que faz Aristóteles (1988) com o seu discurso sobre as virtudes.

Essa tendência responsiva da ética termina por alcançar o seu mais elevado grau de escolasticidade na Idade Média (Agostinho, 1998; Tomás de Aquino, 1954), quando a interrogação ética deu lugar a uma doutrina moral e a um direito universal da cristandade, com artigos muito bem delineados.

$\mathrm{Na}$ modernidade, o caráter normativo da ética adquire matizes universalistas, esta é a grande contribuição de Kant (1996) e passa a estar intimamente associada ao corpo teórico que conforma a doutrina metafísica, jurídica e moral do Estado Moderno, pelo menos na sua tão copiada e criticada versão hegeliana (Hegel, 1986).

Em relação a esse totalitarismo jurídico-metafísico do império da lei (Hinkelammert, 1995), não faltaram vozes que se levantaram criticamente, como é o caso da Escola de Marburgo (Mosés, 1982) e a Escola de Frankfurt (Adorno, 1990; Horkheimer, 2003), trazendo de volta os questionamentos que colocam em relevo a ausência da interrogação.

Nas críticas de Martin Heidegger (2012) à história da Metafísica, encontramos a denúncia de que esta história se esqueceu da pergunta e se tornou a história desse esquecimento. Na esteira dos críticos do mathema moderno (Heidegger, 1996), Emmanuel Lévinas (1974) apresenta a alteridade, seja como rosto ou como exterioridade de um sistema fechado, como a origem que interpela, interroga e põe em questão.

Nessa mesma linha, é possível encontrar, na obra de Martin Buber (2009), um elevado grau de politização dessa interpelação que provém da alteridade que emerge historicamente com feições palestinas, lutando pelo reconhecimento de um povo que pertence a uma terra. O conceito de irrupção em Walter Benjamin (1971), como uma forma intempestiva, não linear e progressiva do tempo, permite ver a interpelação da alteridade com uma nova compreensão do tempo, muito mais vinculado ao passado e à memória que ao futuro e ao progresso, parecido à lei do outro, na concepção metametodológica de Ecléa Bosi (1993) em suas pesquisas sobre o tempo vivo da memória. 
A consulta pelas transformações históricas da pergunta pelo ético revela-nos que, desde os gregos até os nossos dias, houve um processo pelo qual a pergunta foi se esvaindo até emudecer completamente. A pergunta ética primordial, sobre o como devemos viver a vida, aos poucos foi assumindo modelos representativos (Van Frassen, 2011) que a transformaram em código de conduta.

A redução da ética a código de conduta representa um risco para todas as práticas em pesquisa que se propõem uma reflexão sobre as formas como sua produção se encontra ético-politicamente atravessada. O risco consiste em conceber esse atravessamento como meramente normativo e procedimental. O esquecimento da razão original da pergunta ética acaba produzindo, como resultado último, a impossibilidade de entendimento do real sentido do atravessar ético-político na pesquisa.

A pergunta pelo significado do atravessamento ético-político traz em si também uma suspeita. Talvez a referida pergunta paulatinamente tenha sido relegada a uma zona de transparência, isto é, por tão óbvio, deixa de ser objeto de indagação, passando por um estado de normalização, tornando-se assim opaca e emudecida. Isso acabou resultando na separação entre pesquisa e aspectos ético-políticos, como se fosse possível fazer pesquisa sem outros comprometimentos ou vinculações além dos epistêmicos. Esse modelo epistemológico de uma ciência que normalizou ou marginalizou a dimensão ético-política não mais se pergunta pela possibilidade do atravessamento éticopolítico como voz dissonante, que porta em si a vivacidade da questão, já enunciada quando, na História da Psicologia, ganhou voz destacada o social, como História Social da Psicologia.

Por isso, para que a questão do significado do atravessamento éticopolítico nos dê o que pensar (Ricoeur, 1959), é necessário estabelecer um caminho que permita entender o que está implicado como condição da pergunta. Para isso, partiremos da intuição de Edmund Husserl (1998) sobre os conteúdos inerentes à significação, isto é, a "indicação" e a "expressão" na linguagem como formas de dar significado. Essas duas lógicas se constituem para a presente reflexão como duas maneiras de pensar. Uma é chamada de lógica genética explicativa, Erklärende, que se ocupa das condições transascendentes, ou seja, as condições lógicas e estruturais que orbitam a experiência da prática em pesquisa, nesse caso, o fato de que toda pesquisa permite atravessamentos. A outra é chamada de lógica estatístico descritiva, Beschreihende, que se ocupa das modalidades daquilo que aparece no discurso, isto é, como, nesse caso, a pesquisa e o pesquisador estão atravessados por um discurso ético-político. 


\section{Condições trans-ascendentes}

A propósito do tema da pergunta, Heidegger (2012) assinala que ela pode ser explicada em seus próprios termos, isto é, quem, a quem e pelo que se pergunta. Nesse caso, quem pergunta: o pesquisador mesmo. O que se pergunta: pelo significado do atravessamento ético-político. A quem se pergunta: à pesquisa mesma, como experiência de uma trajetória possível de atravessamentos e que aparece em múltiplos discursos. No entanto, ainda desde a perspectiva do esclarecimento dos termos, é possível inquirir pelo "desde onde" da pergunta, pelas suas condições.

Como já enunciado, o primeiro "desde onde", do qual a pergunta pelo atravessamento ético-político deve partir, é a explicação das suas lógicas inerentes, nesse caso duas: genético-explicativa e estatísticodescritiva. Por lógica genética explicativa ou trans-ascendente, entende-se condições de possibilidade que permitem o nascimento da questão, no caso, a pergunta que interroga pelo horizonte no qual o significado do atravessamento ético-político é possível. Em forma de pergunta: o que está implicado e que implicações são produzidas quando se pensa o significado de atravessar?

Questionar-se pela lógica genética explicativa, Erklärende, implica aprofundar o horizonte de possibilidade a partir do qual a pergunta se torna possível. Isso se faz necessário para que assim, a priori, sejam enunciadas, de forma expressa, as categorias implicadas quando se faz a pergunta pelo significado de atravessamento dentro de um campo do saber (Heidegger, 2012). O que está implicado e que implicações são produzidas quando se pensa o significado de atravessar na prática em pesquisa?

Outro fator que a pergunta pelas condições trans-ascendentes pode revelar toca aos prejuízos (Gadamer, 1991) e aos limites do próprio campo e da própria pergunta, fazendo assim com que o caminho empreendido seja mais claro e sólido em seus passos e mais eficaz em suas conclusões. Por prejuízos se entende o conjunto de saberes prévios presentes, de forma expressa ou oculta, em toda construção de conhecimento. Quais saberes éticos e políticos estão previamente supostos no ato mesmo de pesquisar?

O sentido do atravessar já supõe, de maneira implícita, a pergunta pelas fronteiras que estão sendo atravessadas e, nelas, o sentido do próprio atravessar. Só é possível atravessar o que já está alocado, posto aí e acessível como um lugar dado (Heidegger, 2012). Usando uma terminologia de Edmund Husserl, lugar é uma região, pensada sob a forma de linguagem como morada da significação possível, que permite o aparecimento da questão aqui proposta e os seus desdobramentos. "Nós admitimos, por outro lado que as essências regionais, ou os gêneros diferentes que as compõem, servem de 
fundamento a conhecimentos muito ricos e variados" (Husserl, 1996, p 35).

Contudo, diferentemente do conceito de fronteira como aquilo que delimita e circunscreve algo como uma interioridade, por exemplo, uma cidade cercada por muros, pode-se também pensar a fronteira como aquilo que está em frente e que não é algo no qual uma realidade encontra o seu fim, mas sim, a maneira de um espaço de abertura para novas possibilidades. "A fronteira não é onde termina algo, mas sim, como sabiam já os gregos, aquilo a partir de onde algo começa a ser o que é" (Heidegger, 1954. p. 30). A fronteira, então, constitui-se como o limite que abre um espaço de infinitas possibilidades para além do seu interior. O que se abre a partir dessa compreensão de fronteira, essa possibilidade de ir além dos limites, permitirá pensar o tema do significado do atravessamento.

O conceito de fronteira permite considerar uma realidade que se dá fundamentalmente como abertura (Heidegger, 2001), como algo que transborda e não pode ser contido no limiar de uma interioridade ou totalidade fechada (Lévinas, 1971), por exemplo, os protocolos de pesquisa. $O$ emergir de uma realidade que excede a fronteira revela a possibilidade existencial de algo que se posiciona sempre no limiar do mundo circundante do pesquisador. Esse limiar se configura como um "para além" e lhe oferece resistência (Husserl, 1996) sob a forma de alteridade, seja ela do vivido, do escrito ou do lido, presentes na produção social de vida e conhecimento.

Entretanto a primeira e mais fundamental experiência de fronteira possível ao ser humano e, portanto, ao pesquisador se desenvolve na existência como abertura, infinitas possibilidades, a partir da resistência de uma alteridade. Segundo Heidegger (2012, p. 909), “A abertura constitui o ser do aí", as infinitas possibilidades de um poder-ser, a partir do qual a existência se torna possível, um ser e um existir que somos cada um de nós em cada caso, abertos e expostos à resistência de outros.

Aplicando isso à pesquisa em História Social da Psicologia, é possível vislumbrar a prática em pesquisa como uma abertura às múltiplas possibilidades que emergem do espaço social como espaço público e ético de alteridades; uma experiência do social como resistência que possibilita uma história outra, como compromisso, percurso e expressão.

O fato de que o vivido emerge sob a forma de uma abertura que sofre resistência, acaba por produzir impressões que recebem o nome de mundanidade (Heidegger, 2012). A mundanidade como o estar aí vivendo no mundo com outros que oferecem resistência e interpelação se constitui como condição do espaço social, permeado pelo público e pelo ético. Isso se configura como o caráter impressivo de todas as modalidades do vivido, dentre as quais o pesquisar, a modalidade aqui em questão. 
Frente a isso, o significado do atravessar, por antonomásia, parece configurar-se como um movimento de passar de uma região à outra por meio de uma experiência que deixa impressões. No caso, passar da transparente comodidade do interior da fronteira, entendida como espaço da normalização da dissonância, para uma pesquisa vivida e entendida como espaço intersubjetivo de possibilidade cuja constituição fundamental se dá como uma ética social no presente do vivido e do pesquisado.

Até aqui se constatou, por um lado, que a pesquisa em História Social da Psicologia se realiza em espaço público como espaço de alteridades. Por outro, levantou-se a suspeita de que a pergunta pelo significado do atravessamento ético-político pode ter caído no esquecimento em virtude da transparência e normalização protocolar da pesquisa. Agora temos as condições de inquirir sobre as modalidades nas quais se pode fazer um discurso cujo escopo é levar para a prática em pesquisa as reflexões até agora empreendidas.

\section{As modalidades do atravessamento ético-político}

O caminho até agora empreendido caracterizou-se por uma apertada discussão conceitual das estruturas constitutivas do questionamento sobre o significado do atravessamento ético-político, fazendo assim com que o texto assumisse muito mais as facetas de um discurso lógico sobre estruturas do que um relato de uma prática vivencial em pesquisa.

Feitas as considerações sobre a condição fundamental que está implicada na pergunta pelo significado do atravessamento éticopolítico na pesquisa em História Social da Psicologia, na forma de passagem da transparência que normaliza a interrogação que inquieta, pode-se indagar pelas modalidades de como isto se dá na prática do pesquisador, isto é, nos modos de ser de como essa pergunta emerge como possibilidade, se organiza e produz desordem. Essa segunda parte tem a finalidade de pensar e dar o que pensar sobre o significado do atravessamento ético-político na vida e na experiência daqueles que se dedicam a esse campo do saber.

A primeira modalidade de atravessamento que o pesquisador, no exercício da pesquisa faz, é a de produção do conhecimento científico. Esta, em todas as suas expressões, tal como todas as produções humanas, tem um caráter inegavelmente performático (Austin, 1993), isto é, a seu passo marca de múltiplas formas as pessoas, a cultura, a sociedade, a história.

Nesse sentido, o pesquisador é afetado pelo que constrói, ele é sempre uma superfície de alta porosidade (Deleuze \& Guatarri, 2011) na qual se produzem impressões, ainda que inadvertidamente. Não conhecer e não se ocupar dessas impressões não é a prova cabal de 
sua inexistência, mas sim, de que há uma transparência que a faz inadvertida no ato mesmo de pesquisar.

A Psicologia, da qual é possível narrar uma história social, na sua interface com outras áreas e saberes, principalmente a área da Saúde e das Ciências Sociais, certamente produz conhecimento, e este tem uma performatividade, muitas vezes programática, por exemplo, na forma de pesquisa, pesquisa-intervenção, devolutivas, coleta de dados, construção de dados.

É inevitável que essa prática esteja produzindo uma esteira de impressões nas pessoas, na cultura e na sociedade, escrevendo, muitas vezes de forma inadvertida, a história mesma da produção social do conhecimento científico em Psicologia. A explícita inserção do social na História da Psicologia chama a atenção para o fato de que, aquilo que passou inadvertido como realidade resistente e impressiva, pode emergir e ser expresso como história das resistências, história de alteridades e, por último, história daquilo que foi esquecido por haver se tornado transparente.

As pesquisas no campo interdisciplinar da Psicologia, da História, da Saúde e das Ciências Sociais se encontram concentradas, sobretudo em programas de pós-graduação com cursos de mestrado e doutorado e outras instituições, além de toda uma política de avaliação ético-normativa dos protocolos de produção de conhecimento científico.

Não é possível afirmar que as pesquisas produzidas nesses programas e instituições, munidas ou não de uma autorização protocolar ético-política, não produzem efeitos sobre pessoas, sociedade e cultura, tampouco que não estão, mesmo que inadvertidamente, escrevendo sua história social, pois fazer uma pesquisa é também fazer uma história.

Por isso o social na pesquisa em História Social da Psicologia se realiza com o atravessamento ético-político. Isto se dá, pois o pesquisador se debruça sobre as vivências, narradas ou documentadas, e pela pesquisa produz um condensado que será organizado e expresso na forma de texto, que, por sua vez, poderá ser publicado, lido e submetido a outros protocolos de pesquisa. Nesse processo, o pesquisador faz a experiência de ser outro em relação às vivências pesquisadas, em relação ao condensado e ao texto, bem como em relação ao possível leitor ou outro pesquisador; o pesquisador realiza sua condição ético-política de alteridade de alteridades.

Diante disso, poderíamos perguntar: Que História Social da Psicologia está sendo escrita nos relatórios (relatos documentais) de pesquisa, em protocolos de avaliação ética e na epiderme/memória/narrativa das pessoas e comunidades atravessadas pelas práticas de produção de conhecimento científico do campo da Psicologia? Há nelas uma real consciência ético-política que as atravessa e significa? Uma 
possível resposta a essas questões poderia apontar para outra história sobre alteridades, escrita por um pesquisador que é ele mesmo outro, atravessando e atravessado por outros.

O atravessamento ético-político encontra seu sentido último na relação intersubjetiva de alteridades, isto é, ser outro de outros no espaço público como espaço de alteridades e lugar ontológico de toda pesquisa possível. Por sentido último, entende-se aquilo que está na origem e para a qual o atravessamento ético-político tende nas práticas em pesquisa na História Social da Psicologia.

A pergunta ético-política, quando considerada sob uma estratégia pragmático-normativa de controle protocolar, ou ainda sob o regime de uma lógica de custo-benefício, corre o risco de perder o seu próprio sentido ético-político tornando-se um código de conduta e controle social, cuja função é a preservação mínima do participante, da população, do pesquisador e, com ele, da comunidade científica.

O conjunto de normativas que disciplinam as práticas em pesquisa com seres humanos, ao menos no Brasil, pode ser encontrado de forma bem delineada na Resolução CNS/MS 466/2012 (Resolução $466 / 2012$, 2013), em cujo bojo se normatizam também as pesquisas com biodiversidade, biotecnologia, biossegurança, em vista da geração de patentes. Essa normativa transformou a ética de sua forma interrogativa para um conjunto de regras para o exercício da profissão de pesquisador. Estaríamos diante de uma nova ética profissional e de uma nova estratégia de controle social?

O Sistema CEP/CONEP permite evidenciar, de uma forma muito clara, que a produção do conhecimento científico, principalmente com seres humanos, está atravessada por um discurso ético com matizes normativos e que poderiam convergir, ainda que polifonicamente, no vocábulo bioética, tomado aqui em sentido amplo.

A bioética é uma forma moderna de apropriação da ética. Uma forma de apropriação que permite o assim denominado sujeito éticoepistemológico resolver-se politicamente no cumprimento da normativa. O engessamento normativo da ética terminou por convertê-la em um exercício institucionalizado de checklist, do tipo cumpriu ou não cumpriu com a norma regimental da conduta ética em pesquisa. Estaríamos diante de uma ética profissional do pesquisador, uma ética de procedimentos metodológicos politicamente corretos: o controle profissional é uma forma de controle social.

Mesmo no caso de uma normativa orientada pontualmente para a pesquisa em ciências humanas e sociais, que supostamente operam com um baixo perfil invasivo e consequentemente de menor risco para o participante, a lógica fundamental do modelo jurídico não se modifica. Continua-se operando com o modelo de custo-benefício na forma ético-normativa de menor-risco maior-benefício. A gradação de risco e desoneração normativa de um determinado tipo de pesquisa 
atenua o problema burocrático da avaliação de protocolos de pesquisa, mas não consegue enfrentar o problema do atravessamento ético-político porque este é de outra ordem.

O critério de validação ética de uma pesquisa não pode ser o mesmo que valida e autoriza os protocolos de procedimentos. A prática em pesquisa é uma experiência; como tal, sua validade ética se dá pela capacidade de construção de vida, o que permite falar de um atravessamento ético-político de ordem axiológico-existencial. $\mathrm{O}$ protocolo, por sua vez, tem uma finalidade axiológico-pragmática, cuja validação tem o propósito de garantir a adequação entre as exigências de um determinado campo epistemológico e os termos nos quais os procedimentos estão sendo apresentados ou não.

Há de fato uma ingenuidade quando se supõe que as garantias formais de adequação normativa de um protocolo de pesquisa e a sua consonância com o campo epistemológico produzem, como efeito direto, um construto existencial ético-políticamente atravessado. Não há uma correspondência direta entre a bondade formalmente justa de um protocolo de procedimentos em pesquisa devidamente aprovado, e a experiência de vida, ciência e profissão ético-politicamente atravessada.

Portanto, avalizar a eticidade de uma pesquisa na autorização procedimental apresenta-se muito mais como uma inadequação ao campo, ou como impostura intelectual, do que uma proposta que esteja aberta ao atravessamento ético-político.

Não obstante isso, considerando a normativa vigente sobre pesquisa com seres humanos no Brasil e a existência de um sistema nacional de avaliação ética da pesquisa, abre-se a possibilidade de colocar em análise os protocolos de avaliação de pesquisa do Sistema CEP/CONEP. A análise poderia se voltar, de forma especial, sobre as informações relativas a riscos e benefícios da pesquisa, fornecidas pelo pesquisador no cadastro de seu projeto na Plataforma Brasil, bem como às considerações feitas a esse respeito pelo sistema de avaliação, seja para colocar a pesquisa em pendência, aprová-la ou não.

Os documentos que relatam pesquisas, como são as Dissertações, Teses, Artigos entre outros, e os protocolos de avaliação de Projetos pelo Sistema CEP/CONEP, por exemplo, poderão apontar para a necessidade de ouvir a memória/relato, uma escuta que pode tornar visível o fato de que, no caso da produção do conhecimento científico em História Social da Psicologia, podem existir, ao menos, duas histórias: uma, enterrada nos bancos de dados da produção científica e da avaliação ética dessas histórias; e outra, entrincheirada e resistente na memória/narrativa de grupo de pessoas, comunidades e pesquisadores.

Ainda que fundada em um princípio universalista moderno de que o ser humano, sujeito em si mesmo, nunca pode ser reduzido a objeto 
(Kant, 2007), a normativa que versa sobre ética em pesquisa, termina por ajustar esse caráter inobjetivável do ser humano com a fórmula/cálculo da economia política na ética em pesquisa.

Nos casos em que os benefícios são maiores que os riscos e há uma previsão estratégica (Hinkelammert, 1996) e gerencial para administrá-los, então, a pesquisa está permitida, isto é, está absolvida dos riscos que Ihes são inerentes: em função dos benefícios, os participantes se submeterão e suportarão os riscos toleráveis, gerenciados em cada caso como um mal necessário.

Não obstante esse estreitamento ético presente do discurso bioeticista, é importante recordar que a ética aparece na literatura filosófica do mundo ocidental sob a forma de pergunta, uma interrogação inicialmente colocada por Platão (1986) na boca de Sócrates: "como devemos viver a vida?" (p. 99).

A pergunta socrática sobre como devemos viver a vida só é possível porque existe uma condição, a saber: Sócrates está na pólis, no espaço público exercitando, junto com os outros, a maiêutica filosófica. Anterior a isso, existe o fato de o homem estar constituído no mundo como intersubjetividade aberta e passível de afetação por outros, com os quais estabelece relação em um espaço de alteridades que é sempre público.

Daí o porquê da pesquisa e do significado da pergunta ético-política ter, como terreno de fundo, a relação do ser humano com outros seres humanos, na publicidade do espaço vivido porque, assim como o vivido é maior que o pensado, o ético é maior que o controle dos protocolos de avaliação normativa dos procedimentos em pesquisa. A pergunta socrática fez do viver a vida algo sempre de novo interrogável, a vida e o viver não estão isentos de serem postos em questão e, com eles, todas as suas decorrentes produções.

Portanto, ética, pesquisa e sociedade atravessam, por meio das narrativas, as suas histórias. Tanto uma pessoa, na sua rica e complexa singularidade, como uma comunidade, em toda sua exuberante diversidade, assim como o próprio pesquisador na sua experiência profissional, uma vez atravessados pelo acontecimento da Pesquisa Científica, têm histórias para contar ou tornar presentes no agora pontual da vida daqueles que entram em contato com sua textualidade (Ricoeur, 2010), entendida não apenas como texto, mas sim, como inscrições numa superfície (Deleuze, 2009) chamada vida. Essas histórias são construídas no presente do vivido: no modo de ser da comunidade, como condensado de vivências; do pesquisador, como prática de pesquisa e escrita; e do leitor, sob a forma de possível apropriação.

Tudo isso, tecido como uma história de alteridades que sempre se renova em seus modos de ser, pois o leitor pode, no presente do vivido, produzir um condensado que será pesquisado e transformado em texto pelo pesquisador, que, por sua vez, poderá ser novamente 
lido, produzindo com isso uma nova tessitura no processo de construção do conhecimento.

Examinar a produção científica nessa perspectiva demonstra-se como uma tarefa relevante desde o ponto de vista ético e histórico-social, sobretudo desde duas perspectivas. Uma delas, em relação ao questionamento sobre o discurso ético normativo de uma determinada prática de produção do conhecimento organizado, sobretudo na forma de protocolos submetidos à avaliação ética; e, a outra, em relação ao questionamento pelos tipos de relatos que emergem dos atravessamentos das práticas em pesquisa na vida de grupos de pessoas e comunidades, inclusive na vida do pesquisador mesmo.

Certamente o campo da História Social da Psicologia, no que respeita a sua produção científica, não está isento do escrutínio dessas perguntas, de tal forma que é possível inquirir como as pesquisas nesse campo do saber se resolvem em relação à normativa ética, e como essa prática de construção de conhecimento aparece na memória/relato das pessoas, comunidades e pesquisadores atravessados, cada qual à sua maneira, por esta prática denominada pesquisa.

Daí a interrogação: a análise das pesquisas em História Social da Psicologia nos revela um atravessamento ético-político, cuja base é o modo de ser intersubjetivo de história de alteridades, ou denunciam uma prática protocolar que visa garantir uma segurança mínima pautada sobre a lógica de custo-benefício? Pergunta a qual não temos por objetivo respondê-la, mas, antes, deixa-la como questão que dá o que pensar (Ricoeur, 2004) para cada pesquisador que somos cada um de nós em cada caso.

Com isso, podemos observar que os relatórios de pesquisa, tanto na forma de Dissertação, Tese ou artigo científico, como em protocolos de avaliação ética, podem constituir-se como ponto de partida para essa investigação. Documentalmente, é possível colocar esses relatórios e protocolos em análise, considerando que são de domínio público e encontram-se, maiormente disponíveis na forma digital ou podem ser consultados mediante autorização. Nesses documentos, alguns aspectos podem ser altamente significativos na análise, permitindo ver e fazer ver essa relação entre ética, produção de conhecimento e uma sociedade afetada, que constrói memórias/relatos dessa afetação, inclusive sob a forma de esquecimento.

A análise documental permitiria, por exemplo, voltar o olhar para o discurso sobre a relevância da pesquisa, que poderá oferecer uma série de elementos oportunos para se visualizar a forma como o pesquisador se situa frente aos participantes de sua pesquisa. É essa forma de situar-se que confere ao pesquisador este inusitado poder de permissão: dado o grau de relevância, determinado por algum 
cálculo nunca explicitado, o pesquisador se permite legitimamente submeter as pessoas e as comunidades a um determinado protocolo de produção de conhecimento.

Ainda que o protocolo tenha sido desenhado de forma que as pessoas e comunidades participem dialogicamente do processo de construção dessas permissões - o que caracteriza, por princípio, um status de pesquisa-intervenção - permanece a possibilidade de que o protocolo documentado seja tanto confirmado como desmentido pela memória/relato, tanto dos participantes quanto do pesquisador mesmo.

Outro aspecto interessante a ser colocado em análise e que aparece de forma estrutural em muitos relatórios de pesquisa, sobretudo por força da normativa vigente, é o subtítulo "aspectos éticos da pesquisa", em muitos casos assustadoramente subjugado pelo método. Ali é possível visualizar a forma como o pesquisador desenhou seu lugar e seus movimentos em relação à sua população ou participantes, dependendo do tipo de escopo políticoepistemológico da pesquisa.

Esta análise permitirá visualizar o lugar ético-político do pesquisador em termos topográficos e toponômicos ${ }^{1}$, isto é, seu lugar em cena em relação ao lugar de outros, e as permissões para se mover de uma determinada maneira diante de outros nessa cena. A memória/relato de grupo de pessoas, comunidades e do pesquisador talvez permita a construção de outra cena/movimento, distinta daquela documentada no relato de pesquisa: uma topografia e toponomia outras. Aqui, tanto o pesquisador como os participantes da pesquisa guardam uma reserva de alteridade e de exterioridade em relação ao Relatório de Pesquisa.

Outro aspecto sujeito ao escrutínio da análise é a chamada "devolutiva" endereçada aos participantes. Sobre esse tema se faz muito alarde ético-normativo, já que está diretamente associada ao cálculo dos benefícios. Parece ser que a devolutiva termina por se converter na instrumentação dos supostos benefícios que autorizaram as pesquisa, algo assim como a quintessência do politicamente correto em pesquisa.

Do ponto de vista do relatório documental de uma pesquisa será possível tornar visível a forma como o Pesquisador se resolve éticopoliticamente em relação esse suposto compromisso com os participantes. Por outro lado, a memória/relato dos grupos de pessoas, comunidades e do pesquisador poderá mostrar como eles viveram cotidianamente as supostas repercussões da pesquisa, ainda que na forma do uso/ abandono/ esquecimento/ vaga lembrança.

Voltar aos grupos de pessoas, comunidades e pesquisadores para fazer uma pesquisa sobre as pesquisas é algo que causa um estremecimento ético-político: atravessar o que já foi atravessado? Como chegar a esses grupos de pessoas, comunidades e mesmo nos 
pesquisadores, em alguns casos saturados pelas práticas em pesquisa, no limite da alegação queixosa de "bullying epistemológico"? A proposição de uma pesquisa com intenções éticopolíticas comporta em si mesma uma questão da mesma natureza: com que direito podemos nos permitir tal proposição?

Não se crê que haja uma resposta pronta para esta pergunta, pois se houvesse se tornaria imediatamente uma nova norma com todas as suas bondades e vicissitudes. No entanto, de uma forma talvez ainda ingênua, creio que podemos inverter a posta em cena da pesquisa e criar uma nova topografia com uma nova toponomia.

Topograficamente falando, em lugar de ir ao encontro de grupos de pessoas, comunidades e pesquisadores e atravessá-los com nossa prática em pesquisa, convidá-los a que venham até à universidade e adentrem o espaço físico da produção e armazenamento históricodocumental de conhecimento.

Toponomicamente falando, Ihes daremos a permissão de que nos atravessem com seu olhar/memória/narrativa colocando em análise nossas produções, lendo, conhecendo, interrogando e colocando em questão nossa escrita sobre eles. Se a Universidade ainda é um espaço topográfico e toponômico que lhe convém o adjetivo universitas, então, permitir que aconteça neste espaço universitário o encontro de duas ou mais histórias sobre a mesma experiência pode se tornar possível e, talvez, necessário.

Aquilo que originalmente se estruturava como o modo de garantir a relação de alteridade de alteridades no espaço do vivido passou a ser o conjunto de práticas protocolares de pesquisa que visam garantir a segurança das próprias práticas. A resistência se tornou transparente, e a verdade, como aquilo que resiste ao esquecimento, aquilo que os gregos chamaram de alethéia, terminou sendo esquecida.

Nesse sentido os protocolos éticos de pesquisa estão mais para uma estratégia de redução de danos e, portanto, obedecem a uma lógica de custo benefício, do que para uma estratégica que permita a relação vital de construção do espaço público-epistemológico de pesquisa como espaço público/político de alteridades.

\section{4 Últimas considerações}

A bioética, até agora voltada de forma mais pontual para a biomedicina e outras especialidades que operam com intervenções sobre os processos biológicos, com uma carga discursiva depositada sobre o tema da manipulação genética, da reprodução humana e animal, da produção de alimentos, biotecnologia, armas biológicas, tem se apresentado como um conjunto de afirmações e negações que, conforme o caso, estrategicamente validam ou invalidam eticamente estas intervenções e manipulações. 
Mesmo que em algum momento aconteça a emersão de alguma questão ética relevante sobre a vida e suas condições (Dussel, 1998), ato seguido, a interrogação é respondida com os recursos teóricos provenientes de um conjunto de decisões metacientíficas tomadas sobre essências imutáveis, progressos inevitáveis, experimentos replicáveis, resultados verificáveis e verdades irrecusáveis, que ao fim e ao cabo, terminam por interditar a interpelação e a interrogação como possibilidades da vida mesma: a vida é uma pergunta sempre e necessariamente aberta, não uma resposta. A interdição da possibilidade de continuar sendo pergunta, mesmo na prática em pesquisa, é uma forma de morte.

A intuição que permitiu emergir o adjetivo "social" na História da Psicologia advém de uma sensibilidade, como não indiferença em relação à vida, abertura atravessável por uma história que dá possibilidade à morte ou a vida. As histórias vividas, contadas e estudadas nas pesquisas devem sempre permitir perguntar: a história que está sendo pesquisada, pensada e escrita permite que a vida de todos continue sendo possível?

\section{Referências}

Adorno, T. (1990). Dialéctica Negativa (J. M. Ripalda, Trad.). Madrid: Taurus. (Obra original publicada em 1966).

Agostinho. (1998). Solilóquios: A vida feliz (A. Florotti, Trad.). São Paulo: Paulus. (Obra datada aproximadamente em 354).

Arendt, H. (2007). A condição humana (10a ed.). (R. Raposo, Trad.). Rio de Janeiro: Forense-Universitária. (Obra original publicada em 1958).

Aristóteles. (1988). Ética Nicomaquea. Ética Eudemia (J.P. Bonet, Trad). Madrid: Editorial Gredos. (Obra datada aproximadamente em $384 \mathrm{AC}$ ).

Austin, J. L. (1993). Sentido e Percepção. São Paulo: Martins Fontes.

Benjamim, W. (1971). Angelus Novus. [tradução espanhola]. (H. Murena, Trad.). Barcelona: Edhasa. (Obra original publicada em 1955).

Bosi, E. (1993). A pesquisa em memória social. In.: Revista Psicologia, vol(4). São Paulo: USP.

Buber, M. (2009). Una_tierra para dos pueblos. Escritos políticos sobre la cuestión judeo-árabe. (S. Rabinovich, Trad.). Salamanca: Sigueme/UNAM. (Obra original publicada em 1988).

Costa, M. L. (2009). Lévinas: subjetividad, intersubjetividad y ética. Bogotá: Editorial Beunaventuriana. 
Deleuze, G. (2009). Lógica do sentido (5a. ed). (L. R. Salinas Forte, Trad.). São Paulo: Perspectiva. (Obra original publicada em 1969).

Deleuze, G. \& Guattari, F. (1994). Mil Mesetas. (2a. ed). (J . V. Perez, Trad). Valencia: Pré-Texto. (Obra original publicada em 1980).

Dussel, E. (1998). Ética de la Liberación en la edad de la globalización y de la exclusión ( $2 \mathrm{a}$ ed.) Madrid: Editorial Trota.

Eggers Lan, C. (1986). Los filósofos presocráticos. (C. E. Lan \& V. E. Juliá, Trad.). (Presocráticos). Madrid: Gredos. (Textos datados aproximadamente entre $600 \mathrm{aC}$. e $400 \mathrm{aC}$.).

Gadamer, H. G. (1991). Verdad y Método (4a. ed). (A. A. Aparício, Trad.). Salamanca: Sígueme. (Obra original publicada em 1975).

Hegel, G. F. (1986). Filosofía del Derecho [Introducción de Carlos Marx]. (A. M. Monteiro. Sobrenome, Trad.). México, DF: Juan Pablos Editores. (Obra original publicada em 1807).

Heidegger, M. (1954). Vorträge und aufsätze (2a Teil). Pfunllinger: Günther Neske.

Heidegger, M. (1996). L'époque des conceptions du monde. (Traduit de l'allemand par W. Brokmeier). In: Chemins qui ne mènent nulle part. [Nouvelle Edition]. Saint-Amand: Gallimard.

Heidegger, M. (2001). Seminários de Zollikon [Editado por Medard Boss]. (G. Arnhold \& M. de F.A. Prado, Trad.). São Paulo, SP: EDUC; Petrópolis, RJ: Vozes. (Obra original publicada em 1987).

Heidegger, M. (2012). Ser e Tempo [Edição em Alemão e Português]. (F. Castilho, Trad.). Campinas, SP: Editora Unicamp; Petrópolis, RJ: Vozes. (Obra original publicada em 1927).

Hinkelammert, F. (1995). Cultura de la esperanza y sociedad sin exclusión. San J osé, Costa Rica: DEI.

Hinkelammert, F. (1996). El mapa del emperador. Determinismo, caos, sujeto. San José, Costa Rica: DEI.

Horkheimer, M. (2003). Teoría Crítica. (E. Albizu, Trad.). Buenos Aires/Madrid: Amorrortu. (Obra original publicada em 1968).

Husserl, E. (1996). Recherches phénoménologiques pour la constitution. (E. Escoubas Trad.). Livre Second. Paris: PUF. (Obra original publicada em 1952).

Husserl, E. (1998). De la synthèse passive.. (B. Bégout e J. Kessler, Trad.). Grenoble: Millon. (Obra original publicada em 1966).

Kant, I (1996). Crítica de la razón pura. (P. Ribas, Trad.). México-DF: Alfaguara. (Obra original publicada em 1781).

Kant, I. (2007). Fundamentação da metafísica dos costumes. (P. Quintela, Trad.). Lisboa: Edições 70. (Obra original publicada em 1797).

Lévinas, E. (1971). Totalité et infini. Essai sur l'extériorité. Paris: Li Livre de Poche. 
Lévinas, E. (1974). Autrement qu'être ou au-dela de l'essence. La Haye: M. Nijhoff.

Machado, R. (2009). Deleuze, a arte e a filosofia. Rio de Janeiro: Zahar.

Mosés, S. (1982). Système et Révélation. La philosophie de Franz Rosenzweig. Paris: Seuil.

Platón. (1986). Diálogos IV. República (C.E. Lan Trad.). Madrid: Gredos. (Obra datada aproximadamente em $428 \mathrm{aC}$.)

Resolução 466/2012 de 12 de dezembro de 2012 (2012). Dispõe sobre as diretrizes e normas regulamentadoras de pesquisas envolvendo seres humanos. Conselho Nacional de Saúde, Ministério da Saúde. Recuperado de http://conselho.saude.gov.br/resolucoes/reso_15.htm, em 13 de julho de 2015.

Ricoeur, P. (1959). Le Symbole donné à pensé. In: Esprit (n. 27/7-8). Paris.

Ricoeur, P. (2004). Finitud y culpabilidad. Madrid: Editora Trotta.

Ricoeur, P. (2010). Tempo e Narrativa (3 Vol.). (M. V. Martinez de Aguiar, Trad.). São Paulo: Martins Fontes. (Obra original publicada em 1984).

Tomas de Aquino. (1954). Dos hábitos em geral. Das virtudes [Questões 49-79]. In. Tomas de Aquino. Suma Teológica (A. Correia, Trad.). São Paulo: Sedes Sapientie. (Obra datada aproximadamente em 1225)

Van Frassen, B. C. (2011). Scientific Representation. Oxford: Clarendon Press.

\section{Endereço para correspondência \\ Márcio Luis Costa}

Universidade Católica Dom Bosco

Avenida Tamandaré, 6000, Jardim Seminário, CEP 79010-200, Campo Grande MS, Brasil

Endereço eletrônico: marcius1962@gmail.com

Gillianno M. de Castro

Universidade Católica Dom Bosco

Avenida Tamandaré, 6000, Jardim Seminário, CEP 79010-200, Campo Grande MS, Brasil

Endereço eletrônico: gillianno@gmail.com

Recebido em: 12/08/2015

Reformulado em: 21/10/2015

Aceito para publicação em: 20/11/2015

\section{Notas}

* Professor e Coordenador do Programa de Pós-Graduação Mestrado e Doutorado em Psicologia da Universidade Católica Dom Bosco, Campo Grande, MS - Brasil. Doutor em Filosofia pela Facultad de Filosfía y Letras da Universidad Nacional Atónoma de México, México-DF. 
** Mestrando do Programa de Pós-Graduação Mestrado e Doutorado em Psicologia, Universidade Católica Dom Bosco; Campo Grande, MS - Brasil. Graduado em Filosofia, UCDB. Diploma in Teologia (Università Pontificia Salesiana - Torino/Italia). Especialização em François de Salles (Universitè Catholique de Lyon - Lyon/França). ${ }^{1}$ Normas (permissões) para mover-se em um espaço. 